\title{
Robertson's century: The reception and impact of an epoch-making grammar of the Greek New Testament
}

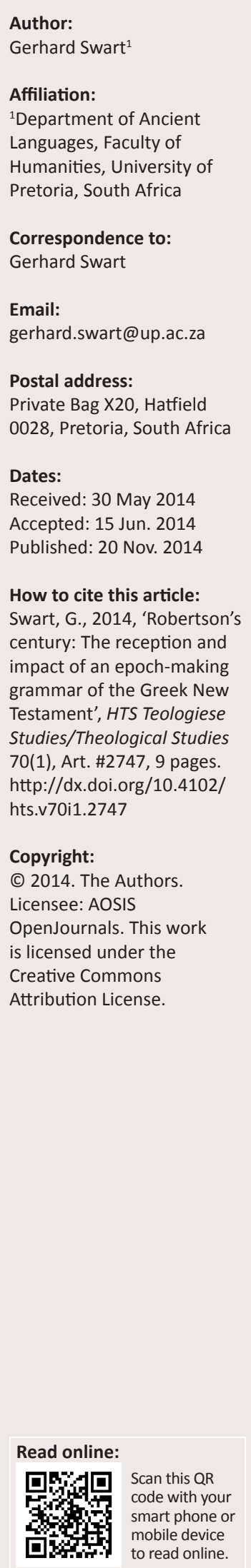

The author endeavours, firstly, to present a vivid account of the reception that A.T. Robertson's A grammar of the Greek New Testament in the light of historical research found in scholarly circles when first published (in 1914) and during the ensuing years; secondly, to probe the question whether, during the course of the past century, the renown of both the man and the book has outlasted the scientific value and the actual utilisation of 'Robertson' in New Testament commentaries and scholarly publications; and thirdly, to address a few grammatical points stated by Robertson that seem to have gone unchallenged despite major shifts affecting the study of language generally, and New Testament Greek specifically, since the publication of his Grammar.

\section{Introduction}

The year 2014 marks not only the 70th anniversary of HTS Teologiese Studies/Theological Studies the oldest theological journal published in South Africa - but also the centennial of the first edition of a widely renowned and highly regarded tool of biblical scholarship: A grammar of the Greek New Testament in the light of historical research by Archibald T. Robertson. The present moment seemed an apt time to conduct a re-appraisal of this great work and to assess the measure of its influence in terms of lasting practical worth - or lack thereof - to users, in comparison with the high esteem in which the book has been held for 100 years since its first publication.

An assessment of this kind obviously must have a double focus: while attempting in all fairness to judge the object of inquiry by the standards and circumstances of the era in which and the readership for whom it was first published, one should also consider the question whether its renown has in fact outlived its usefulness and actual continued utilisation within the present-day context.

First published in 1914, A.T. Robertson's Grammar of the Greek New Testament is still the pinnacle of Baptist biblical scholarship. A time-proven resource that is an essential part of any Greek New Testament student's library. (Amazon n.d.[a])

Since this glowing testimony derives from the web page of a bookseller, it may be dismissed by many as representing nothing but mere sales talk. It does, however, epitomise the enthusiastic praise of Robertson's Grammar expressed from numerous quarters. The book has attracted the attention and admiration of biblical scholars, theologians, classicists, linguists, teachers and students of New Testament Greek - not only during the first quarter of the 20th century, but also, so it seems, in equal measure a century later.

Before returning to the comments and reactions from various circles of readers, it seems in order first to offer some introductory remarks about the author and the book.

Archibald Thomas Robertson was born in the vicinity of Chatham, Virginia, in November 1863. He was converted when 13 years of age, and was licensed to preach in 1879 when only 16 . At the remarkably young age of 32, he succeeded John A. Broadus in 1895 as Professor of New Testament interpretation at the Southern Baptist Theological Seminary in Louisville, Kentucky - a position that he held until his death on 24 September 1934. Although he was also the author of 45 other books, among which his Short grammar of the New Testament (1908; translated into Italian, German, French and Dutch within the following 4 years) and his Word pictures in the New Testament series (6 vols., 1930-1933) are probably the best known, Robertson's monumental work, A grammar of the Greek New Testament in the light of historical research, is generally regarded as his greatest contribution to the field of biblical scholarship. Indeed, it has achieved such renown that one may encounter the mere term 'Robertson' as referring equally to the man or the grammar (cf. e.g. Porter 1992:14).

When Robertson's Grammar came off the press in 1914, it was the fruition of a project begun 26 years before with the encouragement of his father-in-law and predecessor at the seminary in 
Louisville. At roughly 1400 pages, it was - and still is - the largest and most comprehensive New Testament grammar ever published as a single volume written by a single author. The first edition was followed by four more editions by 1931 . The first couple of these reflect the author's own awareness of the inevitability of shortcomings and errors occurring in a project of this magnitude, as well as his refusal to tolerate such imperfections, which is illustrated by the following extract from the preface to the first edition:

If new editions come, as I hope, I shall endeavour to make improvements and corrections. Errata are sure to exist in a book of this nature. Occasionally (cf. Acc. with Inf.) the same subject is treated more than once for the purpose of fullness at special points. Some repetition is necessary in teaching. Some needless repetition can be eliminated later. (Robertson 1914:xi)

The third edition (1919) was, with arguable aptness, described as the 'definitive edition' of Robertson's Grammar (cf. Anon. 1920:210). The aspects in which it differed from the first edition were mainly additions: some features meant to increase the accessibility of material contained in the volume, such as a Table of contents, the expansion of the Index of Greek words to 42 pages - double the size of that in the first edition - and an Additional bibliography to bring the reference list up to date with some relevant literature published during the 5 years that separated the third edition from the first. A section under the heading Addenda to the third edition contains a discussion of this literature and of some resultant modifications of the author's views. Together with an Index of subjects and indexes to the various sets of addenda, these changes increased the size of the volume to 1540 pages.

If all the above details leave the impression of mere attachments pasted onto a document left otherwise unchanged, the reader should bear in mind that the work on this edition was done against the backdrop of World War I, before the advent and therefore without the aid of any of the digital technology that has now become such an integral part of editing and publication. Robertson (1919:xvii) himself was rather modest about the labour spent on the preparation of this edition; compare his statement 'I have watched with eagerness for criticisms of the book and have done my best to turn them to the improvement of the grammar' and his reference to 'the correction of infelicities and errata that could be found here and there' (1919: xviii), with the observation of a meticulously thorough reviewer:

In the text there are about a thousand minor changes, corrections of typesetters' mistakes, misspelled words, and other minor errata. Although a few of these have escaped the author's vigilance, as 'Hist.' for 'Phil.' (p. 536, n. 6), or Goth. he for hwe (p. 249, 1. 12 from below), yet on the whole the purging of errors has been done thoroughly, and the third edition is as accurate as can be expected of a book of such size and complexity. (Petersen 1919:191-192)

Evidently, Professor Robertson still had 'energy and persistence' in store after completing the 'herculean task' of writing and publishing his major Grammar (cf. Parsons 1915:463-464).

\section{Robertson about 'Robertson': Remarks from the preface to the third edition}

The academic and general climate in which Robertson's Grammar first saw the light of day is vividly illustrated by some statements made by the author himself in the preface to the early editions. Quite a few others serve to portray the grammarian, teacher and pastor - his hopes, ideals and joys, but also some of his frustrations:

Perhaps those who pity the grammarian do not know that he finds joy in his task and is sustained by the conviction that his work is necessary. ... I think with pleasure of the preacher or teacher who under the inspiration of this Grammar may turn afresh to his Greek New Testament and there find things new and old, the vital message all electric with power for the new age. That will be my joy so long as the book shall find use and service at the hands of the ministers of Jesus Christ. ... It is gratifying to know that ministers are using [the book] in their studies as one of the regular tools in the shop. In the classroom only selected portions can be covered; but the preacher can use it every day (as many do) in his reading and study of the Greek New Testament. ... solid, critical study ... with commentary, lexicon and grammar ... is the work that pays one a hundredfold in his preaching. (Robertson 1919:x, xv, xvii)

Robertson devotes two paragraphs of the preface to his third edition to a report on the fateful loss of New Testament linguists during the course of the war years since 1914; especially the death at sea, following a German submarine attack, of J.H. Moulton. Despite the sad content, the author's talent for eloquent expression remains unaffected:

Death has been busy with New Testament linguists. Dr. Gross Alexander ... has been claimed by death. Dr. George Heinrici ... is dead. Dr. Albert Thumb ... has likewise passed on. Dr. H. B. Swete ... and Principal James Denney ... have also joined the great majority. These are irreparable losses, but there are others and even greater ones. Dr. Caspar Rene Gregory, of Leipzig, though seventy years old, volunteered for the army and was killed in battle in France. With his death perished the hope of a new and revised edition of Tischendorf's Novum Testamentum Graece for many years to come. A younger man must now take hold of this problem ... Dr. James Hope Moulton fell a victim in April, 1917, in the Mediterranean Sea, ... His death is an unspeakable calamity, but his work will live, for his Prolegomena preserves his interpretation of the New Testament language. (Robertson 1919:xviii)

Then, changing the tone, he continues:

The workers die, but the work goes on. It is pleasant to think that Greek is renewing its grip upon the world. (Robertson 1919:xviii)

And:

There is nothing like the Greek New Testament to rejuvenate the world, which came out of the Dark Ages with the Greek Testament in its hand. ... The Greek New Testament is the New Testament. All else is translation. Jesus speaks to us out of every page of the Greek. Many of his ipsissima verba are here preserved for us, for our Lord often spoke in Greek. To get these words of Jesus it is worthwhile to plough through any grammar and to keep on to the end. (Robertson 1919:xix) 
A modern reader would surely have serious doubts about the New Testament preserving the (Greek!) ipsissima verba of Jesus - but we need to consider that almost a century elapsed since Robertson wrote these words.

\section{Availability and utilisation of 'Robertson'}

In the present context, both its age and its considerable size contribute to the fact that copies of Robertson's Grammar are not freely available in printed format any more. Since the author's death only a few years after the publication of the fifth edition in 1931, no further revisions were undertaken, and the present author found no indication that any reprints had recently been produced. The amazon.com web page lists a 'reprint on demand' version of the 1919 edition, but displays the following notice: 'Currently unavailable. We don't know when or if this item will be back in stock' (Amazon n.d.[b]).

Fortunately, the digital era has come to our aid in countering the scarcity - or even the real prospect of total unavailability - of Robertson's Grammar. Electronic versions have been made available to users via several channels: the third edition (1919) of Robertson is included in Bible Works, along with some reference grammars as far removed from one another, in terms of approach and date of publication, as Burton's Moods and Tenses (1898) and Wallace (1996). The 1919 edition is also the version presently available to users of Logos Bible Software - although not as part of the 15-volume A.T. Robertson collection, which includes Robertson's A short grammar of the Greek New Testament, for students familiar with the elements of Greek, first published by Hodder and Stoughton in 1908.

Electronic versions are also available in the public domain: A scanned copy of the original hardcover version of the first edition is offered in PDF and some other formats on the Internet Archive web page (https://archive. org/). A digitised version of the 1919 edition, prepared by Ted Hildebrandt of Gordon College, Wenham, MA, in March 2006, is available on their web page (http://faculty.gordon.edu/).

Availability is only one side of the picture, however. A more pertinent question is whether the Grammar is still exerting an educational and instructive influence on scholars and exegetes. Is it still widely in use, and is this evident in scholarly publications? In a recent study, Stanley Porter draws a fairly gloomy picture of what he calls 'the linguistic competence of New Testament commentaries' (Porter 2012). His study focuses on the presence - or absence - of references to standard grammars in a selection of commentaries on Matthew, Romans, James and Revelation, in the series ICC, NIGTC, WBC, and BECNT (Porter 2012:33-34). His choice of commentary series is based on the claims, on the part of the series editors as well as individual commentators, to be 'linguistically informed' (Porter 2012:34; cf. 45-46; 51); and his choice of New Testament books merely reflects the fact that these four books receive fuller treatment than the rest in the Festschrift of which his contribution forms a part (Porter 2012:33). By Porter's (2012:51) own admission, the occurrence of citations from grammars can give but a preliminary indication of the works to which commentators typically refer when addressing points of linguistic nature; but this is precisely where his study has relevance for the present discussion of Robertson's impact on New Testament scholarship.

Porter's (2012) observations can be briefly summarised in a few extracts from his article:

Cranfield's ... commentary ... limits its major grammatical observations to the work of Blass and Debrunner in Funk's translation, Moule, and Robertson.

Moo's commentary on Romans attempts to be linguistically informed. Even though he still cites Blass and Debrunner in Funk's translation the most of any Greek grammar, ... in the comparative period he cites the work of ... Beckwith ..., Blass and Debrunner in Rehkopf's revision, Burton, Moulton, Moulton and Howard, Turner, Moule, Robertson, and Zerwick ..., as well as Deissmann. ... Moo actually engages in discussion of their various views.

[Schreiner's] use of grammatical works overall is limited, however, with Blass and Debrunner in Funk's translation clearly being his major source, along with Moule, Robertson (twice), Turner, and Wallace (twice), as well as Deissmann.

Aune's commentary on Revelation is no doubt the most linguistically well-informed commentary examined here. ... displays a firmer grasp than other contemporary commentaries of the comparative-historical period when he cites works by W.J. Aerts, Blass ..., ..., Robertson, ..., ... [27 in total]. (Porter 2012:42, 45-46, 47-48)

In Porter's view, all the above provides but scanty evidence of continued engagement, on the part of New Testament commentators, with developments in the views of linguists and grammarians of the Greek language. For the purposes of this study, however, it does seem noteworthy that 'Robertson' features prominently in all those commentaries that at least claim to be taking the linguistic phenomena of the Greek New Testament seriously.

The present author did not find much evidence of serious engagement with the views of grammarians in the commentaries mentioned above. Moo, for instance, has some 20 references to Robertson, but most of these seem to serve no other purpose than to cite a respected authority for some interpretation or for the use of a particular grammatical term. Consider the following example: The 'ingressive idea' associated with the aorist subjunctive $\pi \varepsilon \rho 1 \pi \alpha \tau \eta \dot{\sigma \omega \mu} \sigma \varepsilon$ in Romans 6:4 is motivated, without any further discussion, simply by way of an appeal to Robertson, page 850 (cited in Moo 1996:366, n. 70). Given the length of Moo's commentary, and the exhaustive detail in which he discusses many other matters, it would seem that many of his references to grammars have little more significance than to pay tribute to respected Greek scholars of a bygone era. 


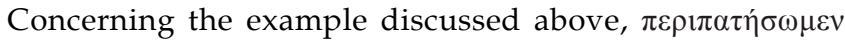
in Romans 6:4, Cranfield (1975:305) comments as follows: 'The use of the aorist ... indicates that the thought is of the beginning of the new way of life which contrasts with the old.' Like Moo, he also does not provide any motivation of this statement - only a footnote that refers his readers to 'BDF, § $337(1)^{\prime}$.

These two instances seem to support Porter's observations: New Testament commentators generally do not make much use of Greek grammars; but when they do, 'Robertson' still features among those most frequently appealed to, despite its considerable age.

We shall presently return to these examples; but firstly let us consider the impact that Robertson had on grammarians of New Testament Greek during the century since 1914.

It would be utterly surprising if Robertson's Grammar were not mentioned, discussed and referenced in modern grammars of New Testament Greek. Porter (1992:315-316) includes it in his list of 20 works - besides his own Verbal aspect in the Greek of the New Testament (1989) - 'worthy of a place in a library of Greek grammar.' He rarely engages his readers in a discussion with Robertson, though. In his chapter on Tense and aspect - understandably the longest but one in his grammar - he cites Robertson directly only four times:

The first of these citations occurs in the context of a brief statement about the 'synchronic treatment' of the Greek verbal system being favoured by modern linguists. This approach is then contrasted to the construction of 'genetic forbearers' [sic], for which he cites Robertson, pp. 46-48 (Porter 1992:28, n. 4). The next three citations consist of mere page references to Robertson - pages 880-882 regarding the present tense ('the imperfective verbal aspect grammaticalized by the present tense-form') being used in various temporal contexts (Porter $1992: 29$, n. 3); to page 841 regarding the probable protoIndo-European origin of aorist forms referring to present action (Porter 1992:36, n. 1); and to pages 895-896 for a view contrary to his own, that the 'force of the stative aspect is that the grammatical subject of the verb is the focus of the state of affairs' (Porter 1992:40, n. 2).

In the next chapter, on Mood and attitude, Porter quotes Robertson's words on two occasions only: In support of his own understanding of the Greek indicative as the 'unmarked' mood: 'the normal mode to use when there is no special reason for employing another mode' (p. 915 - Porter 1992:51, n. 4); and in support of his contention, recognised by many grammarians since Schwyzer, that the indicative does not objectively state reality, but is used subjectively to express what a speaker sees or presents as reality: 'most untruths are told in the indicative mode' (p. 915 - Porter 1992:52, n. 1).

Daniel B. Wallace (1996) provides a Select bibliography at the beginning of each chapter or major section. Robertson's
Grammar features regularly in these lists - see pages $13,36,65$, 73, 138, 176, 207, 292, 316, 356, 390, 408, 443, 495, 513, 540, 554, $566,572,588,613,667$ and 702 . This in itself does not reflect serious engagement with the views of Robertson; ironically, it does illustrate that the latter has discussed every grammatical topic that Wallace addresses (besides many more - 'almost every conceivable aspect of the New Testament language', in the words of an early reviewer [Petersen 1919:191]).

In addition to the page references given in these bibliographies, Wallace refers his readers to 'Robertson' in connection with the following topics: portrayal versus reality, especially in the Greek verbal system (Wallace 1996:10); the eight-case system and Robertson's influence in popularising it (1996:32, n. 4); the significance of the Greek article (with two quotations from Robertson - 1996, 208); the semantics of the article in John 1:1 (1996:268, n. 30); and finally, with regard to the present versus the aorist tense in prohibitions, Wallace $(1996: 715$, n. 5) remarks that Robertson 'commends Moulton's canon [about the aorist as prohibiting an action not yet begun and the present as prohibiting an action that is already in progress] on one page, but backpeddles [sic] for three more on the exceptions'.

For the purposes of the present study, we may focus on two of the above instances.

Firstly, Wallace (1996) states:

One of the fundamental keys to understanding language is the recognition that there is not necessarily any correspondence between language and reality. If such were the case, neither irony nor novels could be penned. Unfortunately, students of scripture (both exegetes and grammarians) too often assume such a correspondence. For example, not infrequently the indicative mood is erroneously considered to be the mood of fact. On this point, A.T. Robertson astutely pointed out: 'The indicative does state a thing as true, but does not guarantee the reality of the thing. In the nature of the case only the statement is under discussion. A clear grip on this point will help one all along. The indicative has nothing to do with reality ("an sich"). The speaker presents something as true .... Whether it is true or no [sic] is another matter. Most untruths are told in the indicative mode.' (p. 10 - quoting Robertson 1923:915)

Robertson, we may observe, sounds decidedly modern and just as 'linguistically informed' (to use Porter's phrase) as Wallace some 70 years later in this passage.

In the second instance, Wallace (1996) testifies, in a rather ironic way, to Robertson's stature as a highly respected grammarian of the Greek language:

On the side of the eight-case system are the grammars by Robertson, Dana-Mantey, Summers, Brooks-Winbery, Vaughan-Gideon, and a few others. Almost all the rest (whether grammars of the NT or of classical Greek) embrace the five-case system. Interestingly, the common thread that runs through the eight-case supporters is that they are typically Southern Baptists (A.T. Robertson's influence is most likely the major reason for the popularity of the eight-case system in that denomination). (Wallace 1996:32 n. 4) 
It may be noted that Robertson would be naturally inclined, given his comparative-historical approach (see point 2 below), to favour the view that the Greek nominal system comprises eight separate cases rather than five. The deciding principle in this issue is whether case be regarded from the perspective of form or function: if form is the norm, only five different cases are actually distinguishable on the basis of inflection; if function (i.e. semantics) prevails, many more uses (i.e., roles of nominal items in propositions) can be identified than the eight 'cases' traditionally distinguished in studies of Indo-European grammar.

\section{Assessment/appraisal of Robertson's Grammar}

As stated in the present paper's introduction, an assessment of the impact of Robertson's Grammar needs to take into account both the circumstances and standards applying at the time of publication, and whether the Grammar is still regarded as valuable in the present-day context. To this end, a brief survey of the major shifts in focus that affected Greek grammatical study over the course of the past two centuries is required. Such a survey can provide a picture of the context within which a book such as Robertson's Grammar was needed. Porter (2012:38-40) distinguishes three main periods in the history of research in the field of Greek grammar:

1. The rationalist period (before 1885) was characterised by 'attempts to make logical and rational sense of language phenomena'. Georg Winer's grammar (1822) was an exemplary result of this approach, which involved efforts to develop grids in which 'a balanced number of forms' was attained by assigning to 'each cell ... its element'.

2. The comparative-historical period (1885-1960) was inaugurated by the work of 'the great comparative philologist' Karl Brugmann. The comparative approach that characterised this period produced grammars in which the Greek of the New Testament was described in terms of its deviations from classical Greek (e.g. Friedrich Blass); was compared to the language of the papyri then recently discovered (e.g. Moulton and Deissmann); or was explained from the perspective of its historical origins. A.T. Robertson was the main exponent of the latter focus.

3. The modern linguistic period (since 1961):

It begins with James Barr's Semantics of biblical language and includes major work done on aspect theory (McKay, Porter, Fanning, and Decker), discourse analysis, and a variety of other areas of study, besides linguistically sensitive grammars (Porter and Young).

One may also complement this survey by Porter's description of phases in the history of the study of Greek verbs - especially how the functions of the tense forms have been variously understood since the ancient grammarians and up to the present time (Porter 1992:26-28). These surveys provide a background against which the following remarks (representing both the era when Robertson's Grammar was first published and the modern linguistic era) may be better understood:
The main justification for the volume ... is the progress which has been made in the last generation in certain lines which are of vital importance to the study of the language of the New Testament. The emergence of the study of language as a historical science would in itself have warranted the undertaking of such a task; while the important and almost amazing discoveries regarding the popular language of the Greco-Roman world made such an undertaking imperative. (Parsons 1915:464)

Professor Robertson's Grammar ... has filled a real want and ... already has displaced its predecessors and become a necessary part of the equipment of every New Testament scholar, as it will be for at least a generation to come. This is due on the one hand to the reworking of New Testament grammar in the light of modern discoveries. It represents the abandonment of the theory that New Testament Greek is to be explained as a Hebraistic corruption of classical Greek, but interprets the same as a stage in the real organic development of the Greek language, namely as an offshoot of the vernacular кoเví, as is shown by the papyri and ostraca. The writer draws on these and the inscriptions as well as the classical Greek literature and the modern Greek to fix the place of the New Testament linguistic phenomena. (Petersen 1919:190-191)

Clearly, Robertson was regarded both as an exemplary representative of the scholarly era to which he belonged, and as a true pioneer who succeeded in translating new realities and new conceptual frameworks into a grammar of exceptional scope and complexity.

Among the points of criticism expressed in reaction to Robertson's Grammar a century ago, some relate to the exact same characteristics for which it earned praise. The most prominent of these is the 'wealth of scholarship' underlying the book (H.L.J.W. 1915:122-123), making it 'a practically complete storehouse of references to the literature of New Testament grammar and allied subjects' (Petersen 1919:191), as well as its 'wonderful comprehensiveness' - but the laudatory remarks were not unqualified:

It is a large book. The reviewer would be glad if he were able to say that it was a great book. But ... it can scarcely be so called. The fault is not with the subject, nor does it inhere in the material at the author's hand. The author himself has failed to make it a great book. The work is uneven in quality. ... A more discriminating attitude as to the material which was necessary and relevant would have resulted in a smaller but surely a better book. (Parsons 1915:465-466)

Another reviewer was less polite, calling the book 'hopelessly and needlessly cumbersome' owing to excessive repetition (H.L.J.W. 1915:123). Robertson's literary style also attracted some critical comments, such as the following:

Some ... defects may be explained as resulting from the adoption of a colloquial style. But one wonders whether such adoption is permissible in a work of this kind even when discussing colloquial Greek. (Parsons 1915:466)

The same reviewer also noticed a lack of clarity, which he attributed to 'loose and careless revision', in Robertson's Grammar.

Perhaps the fact that Robertson was at heart a teacher of the Greek New Testament, and that his Grammar evolved from decades spent in the lecture room as much as it was the product of the grammarian's study, was not duly kept in mind by the reviewer who wrote the following sarcastic remark: 
One scarcely knows whether Dr. Robertson is humorous or serious in such a statement as the following: 'It is hardly worthwhile to warn the inept that there is no connection between the

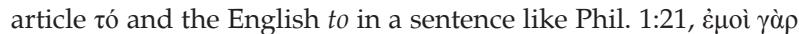

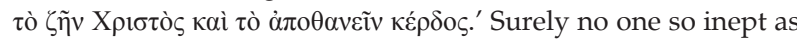
to need even the slightest reminder on this point would be likely to make much use of such a volume as the one under review. Is it not possible that the author slightly underrates the intelligence of his prospective readers? (Parsons 1915:467-468, quoting Robertson 1914:1065)

A true teacher never underestimates the intelligence of his or her students, but is always aware that they arrive at an educational institution 'inept' (i.e. lacking skill), and expect to leave with their ineptitude significantly diminished by the teacher's sensitive intervention. The present author feels compelled, at this point, to record a very recent incident that closely resembles what may be regarded as probably the stimulus that prompted Robertson's comment (the one to which Parsons raised the objection quoted above). During the early morning hours of Monday, 26 May 2014, he came across a second-year student of Greek's rendering

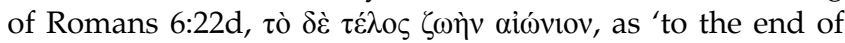
life eternal'. The student's seemingly fallacious equation of the English phrase 'to the end' with $\tau$ ò $\delta \dot{\varepsilon} \tau \varepsilon \dot{\varepsilon} \lambda \mathrm{o}$ at once recalled Robertson's comment; but some reflection brought up three considerations that could explain how said student possibly arrived at this 'inept' rendering: (1) the Greek clause is elliptical, which an intelligent reader would recognise, and would take as a cue to search the immediate context for the implied verb; (2) the preceding clause, to which $\delta \varepsilon$ provides a link, ends in the phrase eis $\dot{\alpha} \gamma 1 \alpha \sigma \mu$ óv, 'unto holiness' (KJV),

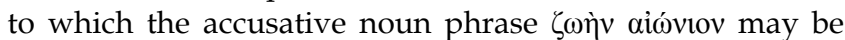
regarded as parallel; and (3) the formulation 'to the end of life eternal' could be intended as expressing an interpretation such as 'and finally, unto life eternal'.

Needless to say, the student received the benefit of the doubt regarding consideration (3), full credit in terms of consideration (2), and incurred no penalty for ineptly (but definitely not unintelligently) disregarding consideration (1) and not arriving at what her professor considers to be the correct contextual rendering, 'and as end result (you have -

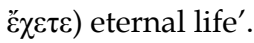

Robertson gave a clear indication of his intended readership in the preface to the first edition of his Grammar (1914):

The present volume is designed for advanced students in theological schools, for the use of teachers, for scholarly pastors who wish a comprehensive grammar of the Greek New Testament on the desk for constant use, for all who make a thorough study of the New Testament or who are interested in the study of language, and for libraries. (p. xi)

The reviewer cited above reacted as follows to this declaration:

The constituency to which appeal is made is a comprehensive one and doubtless there will be those within its limits who will find occasion to consult the work. When they do so there will be many facts and suggestions which will reward them. These would stand out in bolder relief if a considerable amount of repetition had been avoided and if irrelevant material, possibly the collection of the years devoted to preparation and making of the book, had been omitted. (Parsons 1915:468-469)
It seems that the early reviewers were of the opinion that Robertson tended at times to lose sight of his aims in terms of readership, subject material and theoretical orientation. This error may partly be blamed on the extent of time it took to prepare the book - but the same could be regarded as an aggravating factor, if the reviewer were justified in accusing Robertson of 'misleading confidence of judgement on questions about which at best we can only surmise' (Petersen 1919:191).

\section{Robertson on tense: Some (not yet) challenged views}

The following subsection presents a discussion of some issues of specifically grammatical nature - a minute sample, indeed, of the immensely large number treated by Robertson - and attempts to illustrate how a century of inquiry has brought about novel ways of defining, describing and explaining linguistic phenomena, and how these developments affected some views, and the ways of formulating these views, current in Robertson's day.

The examples chosen for this discussion involve tense forms (especially the aorist), as the tenses of the Greek verb, and the semantic (and exegetical) significance of these features of verb morphology, represent the area where modern linguistics arguably has had the greatest impact. It could be enlightening to open the discussion with Robertson's own definition of the term 'tense':

It is from the French word temps, 'time,' and is a misnomer and a hindrance to the understanding of this aspect of the verb-form. Time does come finally to enter relatively into the indicative and in a limited way affects the optative, infinitive and participle. But [time] is not the original nor the general idea of what we call tense. Indeed it cannot be shown of any verb-form that it had originally any reference to time. We must therefore dismiss time from our minds in the study of the forms of the tenses as well as in the matter of syntax. It is too late to get a new name, however. (Robertson 1919:343-344)

This paragraph at once opens several questions and invites a few comments: firstly, how many terms used in grammar are actually 'misnomers'? Secondly, was Robertson thinking of a gradual process in the minds of Greek speakers or of grammarians when he denied the verb forms 'originally' having any temporal reference but conceded that time 'finally' became associated, at least relatively, with (at least) the indicative? Would his understanding of the concept tense have been different, had his overall methodological perspective been other than comparative-historical? It may be significant that the ancient Greek grammarians used the term $\chi \rho$ óvor for 'tenses'. Robertson's awareness of this is attested to by his insertion of the Greek term in his section heading. Finally, if by 1914 it was already 'too late' to find a better name for this feature of verb morphology, do we have any options left in 2014 ?

We may also note that the basic assumption underlying S.E. Porter's theory of 'verbal aspect' in Greek (1989) is a denial of any systematic connection between tense and time-asserting, 
from a linguistic perspective, the same that Robertson said (see the previous quote) from a historical perspective. The essential difference between these two views is that Robertson assumes that an association between tense and time only developed over time, whereas Porter does not acknowledge any such association (ever?) existing in the language. This difference may be regarded as the inevitable result of a difference in approach - a diachronic versus a synchronic perspective. Yet we need to observe that both seek to answer the same basic question: if in Greek there is no one-to-one relation between tense and time - that is, the language has more than one tense possibly referring to the same temporal reality - in what way do the tenses differ semantically (i.e. what semantic distinction is grammaticalised by the choice of one tense or another)? Robertson did not formulate it in the same words, but asked essentially the same question. His answer begins as follows: 'There were originally two types of verb-roots, the punctiliar and the durative' and (1919:344) and ' $[t]$ here were originally two verb-types, the one denoting durative or linear action, the other momentary or punctiliar action' (1919:823).

The differences between the two statements above are significant: Postulating a 'punctiliar' or 'durative' verb-root is not the same as postulating 'verb-types ... denoting' these respective qualities or 'kinds of action' (Aktionsarten). More will be said about Aktionsart in a moment; but note that both statements start with the same phrase - ' $[t]$ here were originally ...' - reflecting once again Robertson's diachronic perspective. Note also that the terms 'punctiliar' and 'durative' are equated with 'momentary' and 'linear' respectively.

The two types of action described as 'original' by Robertson, and as 'basic' by exponents of the synchronic approach (cf. Wallace 1996:499), are complemented by a third, the 'perfect' or 'completed', and these three are jointly regarded as underlying the distinctive categories within the Greek tense system:

The three essential kinds of action are thus momentary or punctiliar when the action is regarded as a whole and may be represented by a dot (.), linear or durative action which may be represented by a continuous line - , the continuance of perfected or completed action which may be represented by this graph -

These ideas (punctiliar, durative, perfected state) lie behind the three tenses (aorist, present, perfect) that run through all the moods. The forms of these tenses are meant to accentuate these ideas. The aorist stem presents action in its simplest form

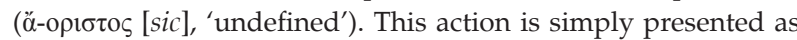
a point by this tense. This action is timeless. The present is also timeless in itself as is the perfect. (Robertson 1919:823, 824)

Opening a discussion of the tenses and their meaning with reference to the indicative mood, or rather 'mode', is another conventional feature of grammars - and unfortunately so, since the use of this mood is complicated by the ever-present association with (temporal) reality. Of this Robertson was also well aware; therefore his repeated efforts to isolate the notion of time from discussions of the tenses (e.g. by statements such as ' $[w]$ e must ... dismiss time from our minds in the study of the forms of the tenses,' or when chiding
Radermacher for using the term Zeitart instead of Aktionsart - Robertson 1919:344, 824). The indicative, it should be noted, generally expresses factual propositions (not facts). Verbs in this mode portray events (i.e. actions, states or processes) as real - related to reality - from a speaker's point of view; and the reality portrayed is understood in terms of the categories past/present/future (as well as omnitemporal and atemporal).

To avoid complicating the present discussion of Robertson's views on 'kind of action' ('Aktionsart') and how these differ from modern grammarians' views on 'aspect' in the verb tenses, it would seem wise to focus on non-indicative examples. The subjunctive mode is used to portray events (i.e. actions, states, or processes) as possible - potentially related to reality - from a speaker's point of view; and the possibility portrayed is understood without reference to the categories past/present/future. Accordingly, a subjunctive clause such as iv $\alpha . . \pi \varepsilon \rho \iota \pi \tau \eta \dot{\sigma} \omega \mu \varepsilon v$ in Romans 6:4 may well serve the purpose of the present discussion. This clause has already been mentioned above - in the context of modern New Testament commentators' use or non-use of 'Robertson' - and it was noted that appeal is made to the latter authority when asserting that the aorist here has ingressive meaning (Moo 1996:366 n. 70; cf. Cranfield 1975:305).

One can only arrive at a decision as to whether this assertion holds true, by examining the clause iv $\alpha$... $\pi \varepsilon \rho \imath \alpha \tau \eta \dot{\sigma} \sigma \omega \mu \varepsilon v$ within the context of Rom 6:1-14: Paul warns his readers against what would be a misguided inference from Chapter 5 , namely, that one could consider to continue committing sin so as to make God's grace increase. His reason for rejecting this absurd notion is that Christians ('we') have, by means of our baptism, become so intimately associated with the death of Christ that we are virtually dead ourselves (cf. v. 11a) -

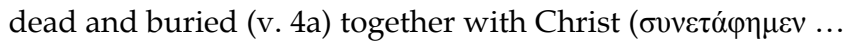
$\alpha v i \tilde{\varphi})$, so that (just as Christ was raised from the dead $-\mathrm{v} .4 \mathrm{~b}$ ) we may likewise also conduct ourselves ('walk') in a new life

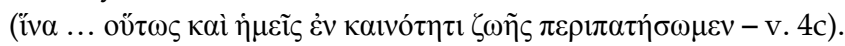

The question to consider now, is whether 'the thought is of the beginning of the new way of life which contrasts with the old' (Cranfield 1975:305; present author's emphasis) - and, pertinently, whether ' $[t]$ he use of the aorist... indicates' this beginning. Surely, the transition (symbolised by baptism) from an old life of sin to the new life in union with Christ, implies a new beginning ('resurrection in the moral sense' - Cranfield 1975:305); but the context does not require a specific focus on the beginning of this new life, as much as on its totality - including its beginning and continuation. Even as 'a foretaste of the final renewal' (Cranfield 1975:305), this new life in its totality is presented as the purpose (or result) of 'being baptised in the death of Christ'. It would have made sense to think of the beginning of this new life, if its realisation were projected into a future context; but that is not the case. The immediate context of Romans 6 suggests that the transition to a new life is presented as having already happened (cf. v. 11). 
It seems that an all too strict understanding of the terms conventionally used to describe the meaning of the Greek aorist tense (especially 'punctiliar' or 'momentary' action) eventually forced interpreters to postulate uses such as 'ingressive aorist'. This concept, with its focus on the moment when an action commences, seemed the only way to reconcile the idea of 'punctiliar Aktionsart' with any action that is portrayed by an aorist verb form, but is not conceivable as

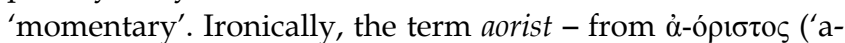
[h]oristos') which means 'boundless' - implies exactly the opposite of 'limited to a single moment', as has been shown by the exponents of modern aspect theory.

The issue should not be oversimplified, however. In the same chapter as the aorist subjunctive discussed above, we find an aorist indicative that can only be understood as signifying the beginning of an action. Romans 6:17 reads:

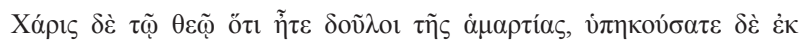

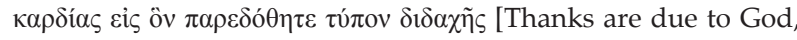
since you were slaves of sin, and/but you obeyed from your heart the one to whom you were handed over ...]

This literal translation highlights the need to consider closely what is meant by the aorist $v \pi \eta \kappa \circ v$ $\sigma \alpha \tau \varepsilon$ (about which Cranfield is silent, despite devoting two full pages to the verse). It can logically not refer to an action of obedience occurring simultaneously with being slaves of sin; it must imply a point of transition, when the addressees' obedience to sin ceased and their obedience to Christ began. Neither can it refer to a 'punctiliar', 'momentary' action. It must imply continuation of the obedience up to the time when the letter was written; otherwise the grounds for thanking God would have been nullified. But note: the aorist tense form itself expresses nothing of all this; it is entirely determined by the context.

Finally, we may note two instances - both of not much more than morphological significance - of statements made by Robertson, that seem to have gone unchallenged, if not entirely unnoticed, since the publication of his Grammar in 1914:

- Robertson's claim (admittedly quoting Brugmann) that the augmented verb 'is an enclitic after the augment like «ै- $\lambda ı \pi \varepsilon^{\prime}$ (1919:365) could surely be readily disproved by any augmented form of any polysyllabic verb stem?

- Robertson's insistence on the identity of the 'temporal' augment with the 'syllabic' - '[b]oth express time and both make use of the syllabic $\varepsilon^{\prime}$ (1919:366) - leads to a rather futile discussion on the 'resulting confusion' or 'confusion of result' of contraction between $\varepsilon$ and the initial vowels (or diphthongs) of verbs. Furthermore, the instances that Robertson cites of the 'non-use of the temporal augment' simply do not support the inference that this 'non-use' is the result of difficulties regarding vowel contraction. A more plausible explanation could be found on the basis of regarding the temporal augment as a lengthening of the initial vowel, which does not come into effect in some cases where the resulting verb form would contain a succession of syllabi consisting of long vowels (excessive 'morphological bulk'? - cf. his statement that the use of the syllabic augment with the historic tenses of the indicative 'was not exactly uniform, being less constant with the past perfect than with the aorist and imperfect' - Robertson 1919:365). The pluperfect's morphological structure, requiring both reduplication and an augment, would impose similar pressures on the resulting verb form, in terms of which the tendency towards less constant occurrence ('use') of the augment seems explicable.

\section{Conclusion}

To keep this study within reasonable limits, the author would offer just three brief concluding remarks - not, it should be noted, strictly related to the three separate sections (aims) of the study, but rather three more general reflections that came to mind during the process of collecting and analysing the information presented above.

From a historical perspective, one could say that the era of inquiry into New Testament Greek to which Robertson belonged was characterised by distinctive new discoveries of linguistic material that compelled scholars to rethink their positions on the place of the New Testament within the (history of the) Greek language. In contrast, the era since the mid-20th century is characterised by a new focus on scientific method; a new way of thinking about language and of describing linguistic phenomena. These changes came about through internal rather than external stimuli. The comparative approach - so characteristic of Robertson's work - has remained part of the scene, but the historical (diachronic) emphasis has made way for the synchronic. This shift in itself has contributed to the obsolescence of even an epoch-making work such as Robertson's Grammar.

Today, a full-fledged modern reference grammar of the New Testament is still a desideratum - and it will probably remain so in the foreseeable future, given the ever increasing pace at which knowledge is communicated as the result of developments in information technology. In the present context, a grammar of the stature of 'Robertson' would probably encumber rather than advance the progress of grammatical knowledge regarding the Greek language of the New Testament - functioning, owing to its monolithic proportions, as an anchorage rather than a compass to guide continuing exploration of this vast expanse.

Porter and Wallace - as representatives of the era of modern linguistic inquiry - exemplify two widely divergent approaches: an exegetical emphasis versus the scientific linguistic method of formulating generalisations in terms of which particular linguistic phenomena may be described or explained. Both - though writing roughly three-quarters of a century later than Robertson - in a certain sense still stand on the shoulders of giants, amongst whom towers A.T. Robertson, and whose number would have been diminished significantly, had Robertson succumbed to fate or fatigue before completing the 'herculean task' of writing his Grammar of the New Testament. 


\section{Acknowledgements Competing interests}

The author declares that he has no financial or personal relationship(s) that may have inappropriately influenced him in writing this article.

\section{References}

Amazon n.d.(a), A grammar of the Greek New Testament in the light of historical research, viewed 01 April 2014, from http://www.amazon.com/Grammar-GreekTestament-Historical-Research/dp/0805413081

Amazon, n.d.(b), **REPRINT ${ }^{* *}$ A grammar of the Greek New Testament in the light of historical research, viewed 30 April 2014, from http://www.amazon.com/ Robertson-1863-1934-Testament-historical-Robertson/dp/B004IOVEZY/ref=cm cr_pr_pb_t

Anon., 1920, Review of Robertson Grammar (1919), The Journal of Hellenic Studies 40 (part 2), 210-211, viewed 8 April 2014, from http://www.jstor.org/stable/625130

Aune, D.E., 1997-1998, Revelation, 3 vols. (1-5; 6-16; 17-22) Word, Waco, TX/ Thomas Nelson, Nashville. (Word Biblical Commentary, 52A-C).

Cranfield, C.E.B., 1975, A critical and exegetical commentary on the epistle to the Romans, vol. I, 6th edn., (entirely rewritten), T.\&T. Clark, Edinburgh. (International Critical Commentary).

Hildebrandt, T., 2006, A grammar of the Greek New Testament in the light of historical research, viewed 23 December 2013, from http://faculty.gordon.edu/hu/bi/ted hildebrandt/new_testament_greek/text/robertson-greekgrammar.pdf

H.L.J.W., 1915, Review of Robertson, Grammar (1914), The Sewanee Review 23(1), 122-123, viewed 08 April 2014, from http://www.jstor.org/stable/27532790
Internet Archive: Community Books, A grammar of the Greek New Testament in the light of historical research, viewed 27 January 2014, from https://archive.org/ details/Grammargreeknewtestamentlighthistoricalresearch.Robertson.1914

John P. Robarts Research Library, University of Toronto, A grammar of the Greek New Testament in the light of historical research, viewed 30 December 2013, from $\mathrm{https}$ //archive.org/details/grammarofgreekne00robeuoft

Moo, D.J., 1996, The epistle to the Romans, Eerdmans, Grand Rapids. (New International Commentary on the New Testament). Openlibrary.org, A Grammar of the Greek New Testament in the light of
historical research, viewed 01 May 2014, from https://archive.org/stream/ grammarofgreekne00robeuoft

Parsons, E.W., 1915, Review of Robertson, Grammar (1914), The American Journa of Theology 19(3), 463-469, viewed 07 April 2014, from http://www.jstor.org/ stable/3155585

Petersen, W. 1919, Review of Robertson, Grammar (1919), The Classical Journal 15(3), 190-192, viewed 08 April 2014, from http://www.jstor.org/stable/3287851

Porter, S.E., 1989, Verbal aspect in the Greek of the New Testament, with reference to tense and mood, Peter Lang, New York.

Porter, S.E., 1992, Idioms of the Greek New Testament, Sheffield Academic Press, Sheffield. (Biblical Languages: Greek Series, 2).

Porter, S.E., 2012, 'The linguistic competence of New Testament commentaries', in S.E. Porter \& E.J. Schnabel (eds.), On the writing of New Testament commentaries: Brill, Leiden/New York. (especially section 4, pp. 38-51)

Robertson, A.T., 1914, A grammar of the Greek New Testament in the light of historica research, Hodder \& Stoughton, George H. Doran Co., New York.

Robertson, A.T., 1919, A grammar of the Greek New Testament in the light of historica research, 3rd edn., revised and enlarged, Hodder \& Stoughton, George H. Doran, New York.

Schreiner, T.R., 1998, Romans, Baker, Grand Rapids. (Baker Exegetical Commentary on the New Testament).

Wallace, D.B., 1996, Greek grammar beyond the basics: An exegetical syntax of the New Testament, Zondervan, Grand Rapids. 